\title{
COVID-19 and type 1 diabetes: dealing with the difficult duo
}

\author{
Subhankar Chowdhury ${ }^{1} \cdot$ Soumik Goswami ${ }^{2}$ (D)
}

Received: 6 June 2020 / Accepted: 16 June 2020 / Published online: 14 July 2020

(C) Research Society for Study of Diabetes in India 2020

\begin{abstract}
Background Coronavirus disease 2019 (COVID-19) has aroused global health concerns, particularly in relation to diabetes where it has been associated with poorer outcomes. The bulk of the evolving evidence in diabetes and COVID-19 relates to type 2 diabetes (T2D). Since there are a significant number of patients with type 1 diabetes (T1D) with unique concerns and challenges during the ongoing COVID-19 pandemic, we reviewed existing literature, relevant websites, and related guidelines to form this narrative review to help address key questions in this area.

Methods We systematically searched the PubMed database up to May 31, 2020, and retrieved all the articles published on T1D and COVID-19.

Results We found 18 relevant articles, each of which carried a part of the evidence regarding the risk of contracting COVID-19 in patients with T1D, effect of COVID-19 on development of T1D, outcomes in T1D with COVID-19, and special management issues in T1D in the light of COVID-19. These have been documented in the present review.

Conclusion COVID-19 with T1D presents special challenges. While the available evidence does shed some light, we need more evidence to deal with this difficult duo.
\end{abstract}

Keywords COVID-19 $\cdot$ SARS-CoV-2 $\cdot$ Type 1 diabetes $\cdot$ Diabetic ketoacidosis

Coronavirus disease 2019 (COVID-19) epidemic caused by severe acute respiratory syndrome coronavirus 2 (SARSCoV-2) emerged in Wuhan, China, in December 2019 and has progressed rapidly into a pandemic since the first quarter of 2020 [1]. COVID-19 is commonly characterised by fever, cough, fatigue, shortness of breath, pneumonia, and other respiratory tract symptoms and may even progress to death in some [2]. Patients with older age, hypertension, male gender, heart disease, cerebrovascular disease, kidney disease, hyperglycemia, or history of smoking have been shown to have a higher risk of developing more severe disease and subsequent mortality [3-6]. There have been several publications from the global scientific community on COVID-!9 in type 2 diabetes (T2D) but markedly fewer looking at type 1 diabetes (T1D). T1D constitutes about 5\% of all diagnosed cases of diabetes and its global incidence is increasing at

Soumik Goswami

dr.soumikgoswami@gmail.com

1 Department of Endocrinology and Metabolism, IPGME\&R and SSKM Hospital, Kolkata, India

2 Department of Endocrinology, Nilratan Sircar Medical College, 138 AJC Bose Road, Kolkata 700014, India about $3 \%$ every year [7]. Given the global burden of T1D and unique challenges in treating T1D (more so in developing nations like India), this narrative review attempts to address key questions regarding COVID-19 and T1D. We systematically searched the PubMed database up to May 31, 2020, and retrieved 18 articles published on T1D and COVID-19 besides looking at relevant websites and related guidelines to form this review.

\section{Risk of contracting COVID-19 in patients with T1D}

Diabetes patients have an increased risk of infection compared with the general population and the risk is even greater in those with T1D than in T2D [8]. These include bacterial, viral, and fungal infections of the respiratory tract, urinary tract, gastrointestinal system (including liver), skin and soft tissue, head and neck, and other systemic infections (e.g. HIV) [9]. This increased risk of infection is due to hyperglycemiainduced immune dysfunction (damage to the neutrophil function, depression of the antioxidant system, and humoral immunity), micro- and macro-angiopathies, and greater requirement of medical interventions in these patients [9]. 
Interestingly, in reports from Italy and China, COVID-19 cases with type 1 diabetes were apparently not reported despite a large number of people being infected and hospitalised [10-12]. Possible explanations for the same include a younger age of T1D patients, lower prevalence of T1D, and overexpression of $\mathrm{CD} 8+\mathrm{T}$ lymphocytes in T1D which might play a protective role $(\mathrm{CD} 8+\mathrm{T}$ lymphocytes show an increased apoptosis leading to lymphocytopenia in SARS-COV2 infection) [13]. However, population cohort studies covering all individuals registered with a general practice in England show that T1D patients do contract COVID-19 infection requiring hospitalisation in some $[14,15]$. Presently, as testing for COVID-19 is still limited and as there could be many asymptomatic individuals with the infection, it remains unclear whether T1DM patients are more likely or less likely to contract COVID-19. A study in regions with a high prevalence of T1D (e.g. Scandinavian region) looking at the prevalence of COVID-19 infection with widespread community screening in those with and without T1D could possibly provide an answer. Since it is well established that uncontrolled hyperglycemia impairs immune function in all forms of diabetes, it would be logical to presume that T1D, particularly if not well controlled, could have an increased risk of infection and intensifying glycemic control could serve as a means of primary prevention $[16,17]$.

\section{Effect of COVID-19 on development of T1D}

Viral infections are well known to be associated with the development of pancreatic autoantibodies leading to T1D in genetically predisposed individuals and coronaviruses were identified as one of the incriminating pathogens in the TEDDY study $[18,19]$. Viral infections trigger autoimmune insulitis and pancreatic $\beta$-cell destruction through several mechanisms - virus amplification cycle and/or circulating viral antigens may directly damage $\beta$-cells and also lead to the release of sequestered islet antigens which are presented by overexpressed major histocompatibility complex class I proteins to the immune system, increasing the risk of autoantibody generation. Viral epitopes sharing homology to autoantigens could lead to cross-reactive antibody production against $\beta$-cells (molecular mimicry hypothesis). Also, viral infection leads to cytokine release and $\mathrm{T}$ cell activation which could hasten the development of T1D in genetically predisposed individuals [20]. SARS-CoV-2 might also bind to ACE2 in the pancreas and cause pancreatic injury, particularly in severe COVID-19 cases, thereby hastening the development of overt T1D in susceptible individuals [21]. As T1D development has already been related to coronavirus respiratory infections, it is very likely that an increasing incidence of T1DM may be triggered by the present pandemic and appropriately designed studies are necessary in this regard. Till such published evidence becomes available, practitioners have to be on an active lookout for the development of T1D after COVID-19 in predisposed individuals. There is a report of an individual presenting with diabetic ketoacidosis (DKA) as an inaugural feature of T1D where DKA symptoms were masked by COVID-19 symptoms; this is an area where we need to be vigilant as well [22].

\section{COVID-19 and T1D-outcomes}

While T2D and its associated comorbidities have established themselves as risk factors for increased hospitalisation, requirement of intensive care, and mortality with COVID-19, early anecdotal reports from global infection hotspots suggested that children with diabetes had a similar disease pattern compared with children without diabetes (less severe manifestations than adults) [23, 24]. On the contrary, a large population cohort study assessing the risk of in-hospital death for individuals registered with a General Practice in England showed that people with T1D had $3 \cdot 50(3 \cdot 15-3 \cdot 89)$ odds of dying in hospital with COVID-19 compared with those without diabetes which was attenuated to $2 \cdot 86$ when also adjusted for previous hospital admissions with coronary heart disease, cerebrovascular disease, or heart failure [14]. However, this study also found a very low absolute risk of in-hospital death for people with diabetes under 40 years of age implying that age was a stronger risk influencer than diabetes status [14]. Another study from England using national diabetes and mortality data showed that the adjusted hazard ratio (HR) for mortality in COVID- $! 9$ with T1D of HbA1c $>10 \%$ compared with HbA1c 6.5-7\% was 2·19 [15]. This study also found a Ushaped relationship between body mass index (BMI) and COVID-19 mortality with HRs for BMI $>40 \mathrm{~kg} / \mathrm{m}^{2}$ compared with $25-29.9 \mathrm{~kg} / \mathrm{m}^{2}$ being $2 \cdot 15(1 \cdot 37-3 \cdot 36)$ for T1D [15]. Evidence from these studies coupled with the fact that glycosylation of ACE2 receptors (which is necessary for cell entry of SARS-COV2) can be boosted by hyperglycemia makes a strong case for intensifying glycemic control for improving outcomes in T1D with COVID-19 [25].

\section{Special management issues in T1D in the light of COVID-19}

a. Effect of chloroquine and hydroxychloroquine: There has been an increase in the use of chloroquine and hydroxychloroquine, both for the prophylaxis and treatment of COVID-19. Both these agents have been reported to cause hypoglycemia in patients with and without diabetes (even in those not on insulin or sulphonylureas) [26, 27]. Chloroquine is postulated to reduce blood glucose (BG) levels by stimulating insulin secretion and also by 
activating Akt to stimulate glucose uptake and glycogen synthase [28]. Hydroxychloroquine decreases insulin degradation at the cellular level, increases intracellular insulin accumulation, and stimulates insulin-mediated glucose transport [27]. There is a published report of an individual with T1D on insulin developing hypoglycemia after taking chloroquine prophylaxis while visiting a malaria endemic area following which this patient even maintained euglycemia without insulin for a temporary period [29]. Therefore, patients with T1D who are administered chloroquine or hydroxychloroquine need to be monitored closely for hypoglycemia and their insulin doses adjusted as necessary.

b. Effect of "lockdown": Many countries across the world have imposed "lockdown" measures with restriction of movement and mandatory quarantine of individuals with or at risk of infection. While these measures have been lifted in certain countries, there is a distinct possibility of re-imposition of these measures if a "second wave" of infection appears. Since T1D is known to be greatly affected by alterations in daily routine, there are concerns that "lockdown" can worsen glycemic control in T1D due to restriction of outdoor physical activity, psychological stress on account of lack of physical interaction with acquaintances, irregular sleep pattern, and intake of less healthy diet $[30,31]$. However, interestingly, there are several publications which have pointed to the contrary - there was either no deterioration in glycemic control or even improvement in glycemic control in T1D during "lockdown", particularly in those who continued exercising and in those who did not go out for work [32-34]. Possible explanations include greater parental control and absence of school-related stress in children and adolescents, eating every meal at home with regular timing and more consistent and precise carbohydrate counting, and reduction of workplace-related stress. Besides slowing of daily activities which might have helped in glycemic control, patients' apprehension of worsening of COVID19 outcomes could have contributed to improved compliance with physician advice resulting in good BG control. However, these studies have primarily looked at adolescents using a hybrid closed loop system and adults using continuous glucose monitoring with good glycemic control at baseline because of which these findings might not be generalisable to those with poorer control and/or not having access to these new technological tools. Another concern is interruption in the availability of insulin and glucose meter test strips in relatively remote area due to logistic issues associated with the "lockdown". In view of this, patients would be well advised to ensure sufficient stocks of essential medical supplies besides maintaining a regular schedule and staying physically active indoors in the interest of good disease control. Patients should be encouraged to pursue in-home physical activity (e.g. bodyweight exercise, jump rope, online lessons) as it can not only help improve glycemic control but also for psychological well-being, since physical activity reduces stress and anxiety and improves mood and sleep quality $[35,36]$.

c. Risk of DKA: While contracting an illness might increase the risk of development of DKA in those with known T1D, there are reports of delayed diagnosis of new-onset T1D leading to presentation with severe DKA [37]. Fear of contracting COVID-19 in a hospital setting, reduced access to hospital emergency departments due to travel restrictions, and hospital services remaining closed for non-COVID-19-related ailments could be some of the causes for this. Another reason could be delayed diagnosis on the part of doctors who are preoccupied with COVID19 and might not consider DKA in the differential diagnosis when a patient presents with suspected symptoms either over the telephone or in person. Certain features of DKA overlap with viral illnesses in children and physicians should be on their toes to look out for polyuria, polydipsia, weight loss, Kussmaul's respiration, and a fruity odour in breath.

d. Prevention of DKA: T1D patients who are ill should be advised to follow "sick day rules" which are recommended for any stressful situation to reduce the risk of DKA [38]. These include the following:

1. Insulin should never be stopped.

2. The insulin dose may need to be increased and it might be necessary to take additional doses of rapid acting insulin to bring down the BG levels (Table 1).

3. BG levels and ketones (especially if BG $>270 \mathrm{mg} / \mathrm{dl}$ ) should be checked every $2-4 \mathrm{~h}$. Check for urine ketones with test strips if blood ketone meter is unavailable.

4. Plenty of non-sweet fluids should be taken to avoid dehydration. Liquids for hydration should contain salt and water and not just plain water (chicken soup, homemade lemonade with both salt and sugar, or clear broths), particularly if vomiting or diarrhoea result in ongoing losses. If appetite is decreased or the glucose level is falling below $180 \mathrm{mg} / \mathrm{dL}$, sugarcontaining fluids should be considered to decrease the risk of starvation ketosis.

5. Regular meals can be replaced with easily digestible food (rice-lentil broths and sugar-containing fluids) to provide energy and avoid starvation ketosis.

6. When the child is feeling sick or vomiting and ketone levels are negative or low (trace or small) with $\mathrm{BG}<$ $180-250 \mathrm{mg} / \mathrm{dL}$, sugar-containing fluids in small amounts (at least $100 \mathrm{~mL} / \mathrm{h}$ ) should be administered to keep BG up. 
7. BG should be maintained between 110 and $180 \mathrm{mg} /$ $\mathrm{dL}$ in otherwise stable individuals.

In the following situations, T1D patients should promptly get in touch with their treating doctor:

1. When not sure what to do

2. If they vomit repeatedly (not able to hold down any food or drink for more than $6 \mathrm{~h}$ )

3. If vomiting persists beyond $2 \mathrm{~h}$ (particularly in young children)

4. If BG stays high for more than $24 \mathrm{~h}$

5. If they develop symptoms which could be indicative of their developing diabetic ketoacidosis (nausea, vomiting, abdominal pain, shortness of breath, confusion).

6. If blood ketones remain elevated $>1.5 \mathrm{mmol} / \mathrm{L}$ or urine ketones remain large despite extra insulin and hydration

7. In very young children $(<5$ years $)$

e. Management of DKA: Intravenous (IV) insulin is the standard of care for DKA but may pose a challenge in present times as it often requires admission to the intensive care unit (ICU). ICU beds may be reserved for or be at full capacity with COVID-19 patients besides ICU admission leading to an inappropriate risk of infection in young people with T1D. In this setting, it may be necessary to manage uncomplicated mild to moderate DKA outside the ICU setting with subcutaneous (SC) insulin [39].

$\mathrm{SC}$ rapid acting insulin analogs reach peak effect in 90-120 min and can be used for the treatment of uncomplicated mild to moderate DKA outside the ICU setting [40]. SC regular insulin is an alternative if rapid acting analogs are unavailable. SC rapid acting analogs (lispro/aspart) can be started at a dose of $0.15 \mathrm{U} / \mathrm{kg} 1 \mathrm{~h}$ after the commencement of IV fluid replacement. BG levels should be monitored every $1-2 \mathrm{~h}$ to maintain levels of around $200 \mathrm{mg} / \mathrm{dL}$ until DKA resolves. SC doses should be injected every $2 \mathrm{~h}$ until DKA resolution and the dose can be brought down to $0.1 \mathrm{U} / \mathrm{kg}$ if BG continues to decrease by $>90 \mathrm{mg} / \mathrm{dL}$ per hour. However, SC insulin may be unsuitable for those with severe dehydration or serious comorbid conditions.

$\mathrm{SC}$ regular insulin every $4 \mathrm{~h}$ can be used if $\mathrm{ph}>=$ 7 at a starting dose of $0.13-0.17 \mathrm{U} / \mathrm{kg}$ which can be subsequently increased or decreased stepwise by 10 $20 \%$ depending on BG values. The dosing frequency can be increased to every $2 \mathrm{~h}$ if acidosis does not improve $[41,42]$.

Basal insulin should be initiated once DKA has resolved and oral intake is tolerated. Once DKA has resolved and the child is able to drink adequately, the remaining volume of calculated fluid and potassium deficit can be administered orally to facilitate early hospital discharge thereby optimising the use of healthcare resources and also reducing the risk of contracting COVID-19. Intramuscular (IM) insulin may be used instead of SC insulin in those with poor tissue perfusion [39].

In individuals with T1D and DKA on continuous glucose monitoring system (CGMS), confirmatory BG monitoring with finger-prick capillary blood glucose should be performed in view of issues with CGMS accuracy in the presence of ketosis and rapidly changing BG levels [39].

f. Psycho-social issues: A questionnaire-based Danish cross-sectional study involving 2430 adult diabetes patients of whom one-third had T1D found that those with T1D were more likely to worry about being significantly affected due to diabetes and not being able to manage

Table 1 Additional doses of rapid acting insulin necessary to bring down the BG levels

\begin{tabular}{|c|c|c|c|c|}
\hline \multicolumn{2}{|l|}{ Ketones } & \multicolumn{3}{|l|}{ Blood glucose } \\
\hline $\begin{array}{l}\text { Blood } \\
(\mathrm{mmol} / \mathrm{L})\end{array}$ & Urine & $>180-250 \mathrm{mg} / \mathrm{dL}$ & $250-400 \mathrm{mg} / \mathrm{dL}$ & $>400 \mathrm{mg} / \mathrm{dL}$ \\
\hline$<0.6$ & Negative/trace & Give ordinary bolus & Add $+5 \%$ TDD or $0.05 \mathrm{U} / \mathrm{kg}$ to ordinary bolus & $\begin{array}{l}\text { Add }+10 \% \text { TDD or } 0.1 \mathrm{U} / \mathrm{kg} \\
\quad \text { to ordinary bolus }\end{array}$ \\
\hline $0.6-0.9$ & Trace/small & Add $+5 \%$ TDD or $+0.05 \mathrm{U} / \mathrm{kg}$ & $\mathrm{Add}+5-10 \%$ TDD or $0.05-0.1 \mathrm{U} / \mathrm{kg}$ & Add $+10 \%$ TDD or $0.1 \mathrm{U} / \mathrm{kg}$ \\
\hline $1-1.4$ & Small/moderate & Add $+5 \%-10 \%$ TDD or $0.05-0.1 \mathrm{U} / \mathrm{kg}$ & Add $+10 \%$ TDD or $0.1 \mathrm{U} / \mathrm{kg}$ & Add $+10 \%$ TDD or $0.1 \mathrm{U} / \mathrm{kg}$ \\
\hline $1.5-2.9$ & Moderate/large & Add $+5-10 \%$ TDD or $0.05-0.1 \mathrm{U} / \mathrm{kg}$ & Add $+20 \%$ TDD or $0.1-0.2 \mathrm{U} / \mathrm{kg}$ & Add $+20 \%$ TDD or $0.1 \mathrm{U} / \mathrm{kg}$ \\
\hline$>=3$ & Large & Add $+10 \%$ TDD or $0.1 \mathrm{U} / \mathrm{kg}$ & Add $+20 \%$ TDD or $0.1-0.2 \mathrm{U} / \mathrm{kg}$ & $\begin{array}{l}\text { Add }+20 \% \text { TDD or } 0.1 \mathrm{U} / \mathrm{kg} \\
\quad \text { to ordinary bolus }\end{array}$ \\
\hline
\end{tabular}

In children and adolescents with pre-illness low $(<0.7 \mathrm{U} / \mathrm{kg} /$ day $)$ or high $(>1 \mathrm{U} / \mathrm{kg} /$ day $)$ insulin requirements, consider using the percentage $(\%)$ calculation

$T D D$, total daily dose of insulin 
diabetes if infected with COVID-19 compared with those with T2D [43]. Therefore, special attention should be given to those with T1D in order to manage their anxieties by providing proper information, counselling, peer support, and access to support helplines.

g. Use of technology: The COVID-19 pandemic has put the spotlight on telemedicine and brought it to the forefront of diabetes management. Telemedicine consultation minimises the risk of virus transmission by maintaining physical distancing thereby alleviating the anxiety of T1D patients and their caregivers. It also avoids the cost, time, and inconvenience of travel and waiting at the reception before consultation thereby increasing time for school or work. However, telemedicine does have its share of limitations including inability to perform a proper physical examination, lack of widespread availability of necessary Internet-related infrastructure in several developing countries, and difficulty to establish rapport and address behavior modification in patients $[44,45]$.

In settings with access to more advanced technology, remote monitoring of electronic data (CGMS, connected insulin pens, connected insulin pumps) enables physicians and other health-care professionals to intervene timely in patients whose condition is deteriorating based on available metrics which could help improve clinical outcomes [46].

The present COVID-19 pandemic has changed the way we deal with a number of diseases including T1D. Since we are in the midst of a relatively new and dynamic situation with evolving evidence, we need to be cautious and also rely on logical thinking and common sense to deal with the difficult duo of COVID-19 and T1D more effectively.

Authors' contributions Both authors have contributed equally in all aspects.

\section{Compliance with ethical standards}

Conflicts of interest The authors declare that they have no conflict of interest.

\section{References}

1. Li Q, Guan X, Wu P, et al. Early transmission dynamics in Wuhan, China, of novel coronavirus-infected pneumonia. N Engl J Med. 2020;382:1199-207.

2. Guan W-j, Ni Z-y, Hu Y, Liang W-h, Ou C-q, He J-x, et al. For the China Medical Treatment Expert Group for Covid-19. N Engl J Med. 2020;382:1708-20.

3. Li X, Xu S, Yu M, et al. Risk factors for severity and mortality in adult COVID-19 inpatients in Wuhan [published online ahead of print, 2020 Apr 12]. J Allergy Clin Immunol. 2020;S00916749(20):30495-4. https://doi.org/10.1016/j.jaci.2020.04.006.
4. Abate SM, Checkol YA, Mantedafro B, Basu B. Prevalence and risk factors of mortality among hospitalized patients with COVID19: a systematic review and meta-analysis.[Submitted]. Bull World Health Organ. 2020. https://doi.org/10.2471/BLT.20.260737.

5. Du RH, Liang LR, Yang CQ, et al. Predictors of mortality for patients with COVID-19 pneumonia caused by SARS-CoV-2: a prospective cohort study. Eur Respir J. 2020;55(5):2000524. Published 2020 May 7. https://doi.org/10.1183/13993003.005242020.

6. Cheng Y, Luo R, Wang K, et al. Kidney disease is associated with in-hospital death of patients with COVID-19. Kidney Int. 2020;97(5):829-38. https://doi.org/10.1016/j.kint.2020.03.005.

7. DIAMOND Project Group. Incidence and trends of childhood type 1 diabetes worldwide 1990-1999. Diabetic Medicine. 2006;23: 857-66. https://doi.org/10.1111/j.1464-5491.2006.01925.x.

8. Carey IM, Critchley JA, DeWilde S, Harris T, Hosking FJ, Derek G. Risk of infection in type 1 and type 2 diabetes compared with the general population: a matched cohort study. Cook Diabetes Care Mar. 2018;41(3):513-21. https://doi.org/10.2337/dc17-213.

9. Casqueiro J, Casqueiro J, Alves C. Infections in patients with diabetes mellitus: a review of pathogenesis. Indian $\mathrm{J}$ Endocrinol Metab. 2012;16(Suppl 1(Suppl1)):S27-36. https://doi.org/10. 4103/2230-8210.94253.

10. Grasselli G, Zangrillo A, Zanella A, Antonelli M, Cabrini L, Castelli A, et al. COVID-19 Lombardy. ICU network baseline characteristics and outcomes of 1591 patients infected with SARS-CoV-2 admitted to ICUs of the Lombardy Region, Italy. JAMA. 2020. https://doi.org/10.1001/jama.2020.5394 [Epub ahead of print].

11. $\mathrm{Wu} \mathrm{Z,} \mathrm{McGoogan.} \mathrm{Characteristic} \mathrm{of} \mathrm{and} \mathrm{important} \mathrm{lessons} \mathrm{from} \mathrm{the}$ Coronavirus disease 2019 (COVID-19) outbreak in China: summary of a report of 72314 cases from the Chinese Center for Disease Control and Prevention. JAMA. 2020. https://doi.org/10.1001/ jama.2020.2648.

12. Fadini GP, Morieri ML, Longato E, Avogaro A. Prevalence and impact of diabetes among people infected with SARS-CoV-2. J Endocrinol Invest. 2020. https://doi.org/10.1007/s40618-02001236-2 [Epub ahead of print].

13. Pitocco D, Tartaglione L, Viti L, Di Leo M, Manto A, Caputo S, et al. Lack of type 1 diabetes involvement in SARS-COV-2 population: Only a particular coincidence? Diabetes Research and Clinical Practice. 2020. https://doi.org/10.1016/j.diabres.2020. 108220.

14. https://www.england.nhs.uk/wp-content/uploads/2020/05/ valabhji-COVID-19-and-Diabetes-Paper-1.pdf. Accessed on $28^{\text {th }}$ May 2020.

15. https://www.england.nhs.uk/wp-content/uploads/2020/05/ Valabhji-COVID-19-and-Diabetes-Paper-2-Full-Manuscript.pdf. Accessed on $28^{\text {th }}$ May 2020.

16. Kiselar JG, Wang X, Dubyak GR, El Sanadi C, Ghosh SK, Lundberg K, et al. Modification of-defensin-2 by dicarbonyls methylglyoxal and glyoxal inhibits antibacterial and chemotactic function in vitro. PLoS ONE. 2015;10.

17. Bornstein SR, Rubino F, Khunti K, Mingrone G, Hopkins D, Birkenfeld AL, et al. Practical recommendations for the management of diabetes in patients with COVID-19. Lancet Diabetes Endocrinol. 2020;8:546-50.

18. Caruso P, Longo M, Esposito K, Ida Maiorino M. Type 1 Diabetes triggered by covid-19 pandemic: A Potential outbreak? Diabetes Res Clin Pract. 2020. https://doi.org/10.1016/j.diabres.2020. 108219.

19. Lönnrot M, Lynch KF, Elding Larsson H, et al. Respiratory infections are temporally associated with initiation of type 1 diabetes autoimmunity: the TEDDY study. Diabetologia. 2017;60:193140. https://doi.org/10.1007/s00125-017-4365-5. 
20. Op de Beeck A, Eizirik DL. Viral infections in type 1 diabetes mellitus-why the $\beta$ cells? Nat Rev Endocrinol. 2016;12:263-73. https://doi.org/10.1038/nrendo.2016.30.

21. Liu F, Long X, Zhang B, Zhang W, Chen X, Zhang Z. ACE2 expression in pancreas may cause pancreatic damage after SARSCoV-2 infection. Clinical Gastroenterology and Hepatology. 2020. https://doi.org/10.1016/j.cgh.2020.04.040.

22. Diabetes Metab. 2020;S1262-3636(20):30081-1. https://doi.org/10. 1016/j.diabet.2020.05.004.

23. Guan WJ, Liang WH, Zhao Y, et al. Comorbidity and its impact on 1590 patients with COVID-19 in China: a nationwide analysis. Eur Respir J. 2020;55(5):2000547. Published 2020 May 14. https://doi. org/10.1183/13993003.00547-2020.

24. https://www.touchendocrinology.com/insight/covid-19-infectionin-people-with-diabetes/. Accessed on $30^{\text {th }}$ May 2020.

25. Brufsky A. Hyperglycemia, hydroxychloroquine, and the COVID19 pandemic. J Med Virol. 2020:6.

26. Goyal V, Bordia A. The hypoglycemic effect of chloroquine. J Assoc Physicians India. 1995;43(1):17-8.

27. Salman PM, Quevedo I, Arias M, et al. Hypoglycemia due to hydroxychloroquine, an uncommon association but to keep in mind, case report and review of literature. J Diabetes Metab Disord Control. 2020;7(1):6-7. https://doi.org/10.15406/jdmdc. 2020.07.00193.

28. Halaby MJ, Kastein BK, Yang DQ. Chloroquine stimulates glucose uptake and glycogen synthase in muscle cells through activation of Akt. Biochem Biophys Res Commun. 2013;435(4):708-13. https:// doi.org/10.1016/j.bbrc.2013.05.047.

29. Baretić M. Case report of chloroquine therapy and hypoglycemia in type 1 diabetes: what should we have in mind during the COVID19 pandemic? [published online ahead of print, 2020 Apr 13]. Diabetes Metab Syndr. 2020;14(4):355-6. https://doi.org/10.1016/ j.dsx.2020.04.014.

30. Brazendale K, Beets MW, Weaver RG, et al. Understanding differences between summer vs. school obesogenic behaviors of children: the structured days hypothesis. Int J Behav Nutr Phys Act. 2017; 14:100

31. MacMillan F, Kirk A, Mutrie N, et al. A systematic review of physical activity and sedentary behavior intervention studies in youth with type 1 diabetes: study characteristics, intervention design, and efficacy. Pediatr Diabetes. 2014;15:175-89.

32. Bonora BM, Boscari F, Avogaro A, Bruttomesso D, Fadini GP. Glycemic control among people with type 1 diabetes during lockdown for the SARS-CoV-2 outbreak in Italy [published online ahead of print, 2020 May 11]. Diabetes Ther. 2020:1-11. https:// doi.org/10.1007/s13300-020-00829-7.

33. Tornese G, Ceconi V, Monasta L, Carletti C, Faleschini E, Barbi E. Glycemic control in type 1 diabetes mellitus during COVID-19 quarantine and the role of in-home physical activity [published online ahead of print, 2020 May 21]. Diabetes Technol Ther. 2020. https://doi.org/10.1089/dia.2020.0169.

34. Beato-Víbora PI. No deleterious effect of lockdown due to COVID19 pandemic on glycemic control, measured by glucose monitoring, in adults with type 1 diabetes [published online ahead of print,
2020 May 12]. Diabetes Technol Ther. 2020. https://doi.org/10. 1089/dia.2020.0184.

35. Chen P, Mao L, Nassis GP, et al. Coronavirus disease (COVID-19): the need to maintain regular physical activity while taking precautions. J Sport Health Sci. 2020;9:103-4.

36. Peluso MA, Guerra de Andrade LH. Physical activity and mental health: the association between exercise and mood. Clinics (Sao Paulo). 2005;60:61-70.

37. Cherubini V, Gohil A, Addala A, et al. Unintended consequences of COVID-19: remember general pediatrics [published online ahead of print, 2020 May 8]. J Pediatr. 2020;S0022-3476(20):30578-3. https://doi.org/10.1016/j.jpeds.2020.05.004.

38. Laffel LM, Limbert C, Phelan H, Virmani A, Wood J, Hofer SE. ISPAD Clinical Practice Consensus Guidelines 2018: sick day management in children and adolescents with diabetes. Pediatr Diabetes. 2018;19(Suppl 27):193-204. https://doi.org/10.1111/ pedi.12741.

39. https://cdn.ymaws.com/www.ispad.org/resource/resmgr/covid19/ covid-19 role_of_subcutaneou.pdf. Accessed on $1^{\text {st }}$ June 2020.

40. Swan KL, Weinzimer SA, Dziura JD, et al. Effect of puberty on the pharmacodynamic and pharmacokinetic properties of insulin pump therapy of youth with Type 1 diabetes. Diabetes Care. Jan 2008;31(1):44-6.

41. Cohen M, Leibovitz N, Shilo S, Zuckerman-Levin N, Shavit I, Shehadeh N. Subcutaneous regular insulin for the treatment of diabetic ketoacidosis in children. Pediatr Diabetes. June 2017;18(4): 290-6.

42. Fisher JN, Shahshahani MN, Kitabchi AE. Diabetic ketoacidosis: low-dose insulin therapy by various routes. N Engl J Med. 1977;297(5):238-41.

43. Joensen LE, Madsen KP, Holm L, et al. Diabetes and COVID-19: psychosocial consequences of the COVID-19 pandemic in people with diabetes in Denmark-what characterizes people with high levels of COVID-19-related worries? [published online ahead of print, 2020 May 11]. Diabet Med. 2020. https://doi.org/10.1111/ dme.14319.

44. Espinoza J, Shah P, Raymond J. Integrating continuous glucose monitor data directly into the electronic health record: proof of concept [published online ahead of print, 2020 Jan 6]. Diabetes Technol Ther. 2020. https://doi.org/10.1089/dia.2019.0377.

45. Garg SK, Rodbard D, Hirsch IB, Forlenza GP. Managing newonset type 1 diabetes during the COVID-19 pandemic: challenges and opportunities [published online ahead of print, 2020 Apr 17]. Diabetes Technol Ther. 2020. https://doi.org/10.1089/dia.2020. 0161.

46. Castle JR, Rocha L, Ahmann A. How COVID-19 Rapidly transformed clinical practice at the Harold Schnitzer Diabetes Health Center now and for the future [published online ahead of print, 2020 May 22]. J Diabetes Sci Technol. 2020:1932296820929368. https://doi.org/10.1177/1932296820929368.

Publisher's note Springer Nature remains neutral with regard to jurisdictional claims in published maps and institutional affiliations. 